\title{
Educação como aprendizagem da vida
}

\section{Education as learning of life}

\author{
Maria da Conceição X. de Almeida*
}

\begin{abstract}
RESUMO
Uma sociedade-mundo que oscila entre a ocidentalização do planeta e a diversidade cultural, entre progresso e miséria, e entre as "alternativas de metamorfose da sociedade ou sua catástrofe" (MORIN, 2008a, p.38) parece ter na educação uma chave importante para enfrentar o cenário de incerteza que caracteriza nosso futuro comum. Ultrapassar a fragmentação dos conhecimentos, religar saberes e transpor as deficiências da sociedade da informação configura o horizonte aberto do conhecimento complexo e de uma reforma do pensamento e da educação. "Educar para a vida" passa a ser, segundo Edgar Morin, o papel e a missão da educação afinada com uma ecologia das idéias.
\end{abstract}

Palavras-chave: Educação; aprendizagem; complexidade.

\begin{abstract}
A world-society that ranges from the Westernization of the world to cultural diversity, from progress to poverty, and from the "society's metamorphosis alternatives or its disaster" ( MORIN, 2008a, p.38) seems to have in educa-

* Antropóloga. Professora da Universidade Federal do Rio Grande do Norte - Brasil. Doutora em Ciências Sociais pela PUC-SP. Professora dos Programas de Pós-Graduação em Educação e em Ciências Sociais da Universidade Federal do Rio Grande do Norte. Coordenadora do Grupo de Estudos da Complexidade - GRECOM. Membro da Association International pour la Pensée Complexe - Paris. Membro do Conselho Científico Internacional da Multiversidad Mundo Real Edgar Morin (Hermosillo - México). Membro do Conselho da Catedra para la Transdisciplinaridad (Valladolid - Espanha). Correio eletrônico: calmeida17@hotmail.com
\end{abstract}


tion an important key to face the scenario of uncertainty that characterizes our common future. Overcoming the fragmentation of knowledge, reconnect knowledge and transpose the shortcomings of the information society set the open horizon of complex knowledge and a reform of thought and education. 'Educating for life' becomes, according to Edgar Morin, the role and mission of education tuned with an ecology of ideas.

Keywords: Education; learning; complexity.

\section{Sinais de um tempo}

Multiplicaram-se cada vez mais os diagnósticos sombrios a respeito da sociedade globalizada: hegemonia da ocidentalização do planeta, emergência de fundamentalismos adormecidos, imposição de uma "monocultura da mente" (SHIVA, 2003). São fartos também os estudos e pesquisas que tratam dos eminentes desastres ecológicos de grandes proporções, das condições subumanas dos excluídos do desenvolvimento econômico, da crescente violência das grandes e médias cidades, dos resultados imprevisíveis da biotecnologia, do desequilíbrio crescente entre o exponencial avanço tecnológico e a diversidade de formas culturais tradicionais de viver e conhecer. Ao lado desses diagnósticos sombrios, prognósticos que enxergam uma luz no final do túnel informam que vivemos um momento de grandes transformações levadas a efeito pelo fim das fronteiras intercontinentais, mas advogam ser possível identificar, escolher e projetar forças de regeneração capazes de desviar o trajeto de uma catástrofe final. Jöel de Rosnay chama essas forças de regeneração de "fatos portadores de futuro" e, no livro $O$ homem simbiótico (1997), elege alguns dos cenários capazes de iluminar a simbiose homem-terra-vida-política-econômia-cultura. Edgar Morin, para quem vivemos entre a "alternativa de metamorfose da sociedade ou sua catástrofe", argumenta em favor de uma reforma do pensamento e da educação, de modo a ultrapassar a fragmentação do conhecimento e a reformalizá-lo em patamares afinados com uma ecologia das idéias e da ação.

Do interior de um metasistema narrativo que interconecta diagnósticos sombrios e prognósticos de esperança, a educação emerge como um lugar de apostas essenciais para compreender e agir num mundo imerso na incerteza. Certamente que agora, como sugere Edgar Morin, é necessário ultrapassar o entendimento da educação como unicamente instrução e ensino formativo de uma profissão. Para ele, 
[...] la educacion no puede reducirse a la enseñanza, pues su misión está vinculada diretamente al proceso de vivir. Aprender a vivir es el objeto de la educación, y essa aprendizaje necesita transformar la información en conocimiento, las conocimientos en sapiencia (sabiduría y ciencia) e incorporar essa sapiencia a la vida (MORIN, 2008a, p.35).

Daí porque a reforma da educação precisa contemplar dois planos de reflexão, um pragmático, outro paradigmático, sendo esse último de importância crucial. No que se refere à transformação da informação em conhecimento e desse último em sabedoria, cabem aqui as questões fundamentais colocadas por T. S. Eliot: "Onde está o conhecimento que perdemos na informação? Onde está a sabedoria que perdemos no conhecimento?" (apud MORIN, 2000).

\section{Para pensar bem}

Informação, conhecimento, sabedoria. Essas três palavras são usadas apressadamente como se fossem sinônimas, como se significassem a mesma coisa. Mas é preciso, por um lado, distingui-las; por outro, compreender que da metamorfose da primeira para a segunda e da segunda para a terceira depende, em grande parte, de saber pensar bem para enfrentar e conviver com os enormes problemas e desafios colocados hoje nos níveis local e global.

Podemos dispor de informações e não construir conhecimento algum. Um computador, por exemplo, acumula milhões de informações e dados sobre diversos temas e fenômenos, e nem por isso produz conhecimento. Estocagem de informação não é conhecimento, daí falarmos em "banco de dados", expressão que denota o sentido da sociedade capitalista, bancária, mercantil. O problema é o que fazemos com as informações estocadas. Às vezes não fazemos muita coisa e nos limitamos a anunciá-las em profusão, sem estabelecer nenhuma relação entre elas.

Podemos ser proprietários de um grande banco de dados, ser possuidores de muitas e valiosas informações e, mesmo assim, não construir conhecimento. Os conteúdos transmitidos nas escolas e universidades funcionam muitas vezes assim. São repassados muitos conteúdos, muitas informações, porém os alunos não são instigados a pensar sobre eles, a conectá-los, a estabelecer relações. O sistema educacional se torna, assim, um mercado de informações e forma alunos-bancos-de-dados. Mesmo com a cabeça cheia de informações, eles não 
sabem como articular tantos e tão importantes dados. É nesse sentido que Edgar Morin relembra Montaigne, para quem é melhor ter uma cabeça bem-feita do que cheia de informações.

Para conhecer é preciso selecionar informações, eleger algumas como mais importantes, articulá-las entre si, imputar significados a elas. Conhecimento é tratamento de informações. É o resultado de uma ação e de um trabalho ao mesmo tempo árduo e prazeroso do pensamento para estabelecer elos entre os dados, observar aproximações e afastamentos, procurar encaixes entre indícios e sinais que reconhecemos como informações sobre um fenômeno, um problema, um tema. Conhecimento é manipulação cognitiva, trabalho artesanal do pensamento, como se o pensamento tivesse mãos para dar forma ao que vemos, ouvimos, sentimos, tocamos, apreciamos. Essa manipulação das informações para construir conhecimento se assemelha ao trabalho do oleiro que, com suas mãos, dá forma ao barro que se torna pote, panela ou telha.

A analogia entre o pensamento e o oleiro permite dizer também que informações e barro são as matérias primeiras a serem lapidadas pelos dois artesãos - o artesão do pensamento e o artesão do tijolo e da telha. Daí porque podemos ampliar, com justa medida, a compreensão do que seja um intelectual. Intelectual não é sinônimo de cientista ou acadêmico. Intelectual é, mais propriamente, aquele que faz da tarefa de transformar informações em conhecimento uma prática sistemática, permanente, cotidiana. É aquele que se esmera em manter viva a curiosidade sobre o mundo à sua volta; aquele que observa as várias faces do mesmo fenômeno, as informações novas, contraditórias e complementares; aquele que apura o olhar; aquele que não se contenta com uma só interpretação, nem se limita a repetir o que já disseram.

O intelectual é aquele que manipula, constantemente a mesma interpretação, inserindo-a num campo maior, observando suas transformações, dialogando com ela, pensando sobre ela em outros contextos próximos e distantes. O intelectual é o artista do pensamento, porque dá forma a um conjunto de dados aparentemente sem sentido e desconexos. Onde quer que se opere essa complexa arte do pensamento aí está em ação um intelectual. Por isso, podemos falar em intelectuais da tradição. Eles são os artistas do pensamento que, distantes dos bancos escolares e universidades, desenvolvem a arte de ouvir e ler a natureza à sua volta.

E a sabedoria? Todos os que transformam informação em conhecimento constroem sabedoria? Não! Sabedoria não é o mesmo que conhecimento. O século 21 tem sido chamado de século da informação e fala-se muito hoje em sociedade do conhecimento. Vivemos, é verdade, em meio a um bombardeio de informações, consolidamos muito conhecimento, mas temos à nossa disposição um banco de sabedoria? Pode até ser que sabedoria seja um tipo, uma forma 
especial ou um determinado modo de ser do conhecimento, mas nem todo conhecimento se expressa ou se expande em sabedoria. Ela parece ser mais um jeito de viver e sentir do pensamento, uma maneira de falar do mundo que associa simplicidade e sentimento de parentesco, coragem e afeto, vontade de verdade e consciência da incompletude e do erro. Sendo maior, mais plena, mais essencial e duradoura, a sabedoria não se reduz a um conjunto de conhecimentos.

A sabedoria é o que sobrevive em meio à superpopulação das idéias, dos conceitos, das informações. Quando dizemos que "somos um dos fios da teia da vida", quando assumimos para nós próprios a idéia de que vida é uma teia, estamos anunciando e vivendo uma sabedoria, porque as teorias podem mudar, informações novas podem aparecer, mas apesar dessas mudanças podemos continuar dizendo "a vida é uma teia de muitos fios e nós somos um desses fios". O conhecimento se transforma, porém a sabedoria fica porque fala do essencial e permanente que se desdobra nos fenômenos, no particular, no fugaz, no instantâneo.

Um dos grandes desafios do nosso século é saber ler bem um mundo imerso na incerteza. É saber escolher e tratar informações; é transformar informações em "conhecimento pertinente", ou seja, aquele "capaz de situar qualquer informação em seu contexto", como ensina Edgar Morin (2000, p. 15); é exercitar, aprender e ensinar uma "ecologia das idéias e da ação"; é compreender sabedorias antigas, que nem por isso estão mortas, porque ainda falam do essencial que permanece; é facilitar a emergência de novas sabedorias; é buscar complementaridades em saberes que se opõem. Saber ler bem o mundo de hoje é fazer uso de nossa "inteligência geral" tão adormecida pelos conhecimentos compartimentados e pela cultura das especialidades. Pensar bem no século 21 é fazer do pensamento uma teia tecida de muitos conhecimentos, compreender o que eles têm de essencial.

Mas existe, no final das contas, uma leitura nota dez? Haverá uma medida, um critério, um método, uma condição de ler perfeitamente os fenômenos do mundo? Não! O conhecimento é sempre parcial e provisório, como mostram as ciências da complexidade e como anuncia o pescador e intelectual da tradição Francisco Lucas da Silva a respeito da ciência: "Os próprios cientistas, com todas as máquinas, às vezes prevêem uma coisa e dá errado. A natureza está sempre evoluindo. Então, pode haver algum problema e muda todo o esquema. A natureza é um corpo vivo" (SILVA, 2007, p. 21). Entretanto, se não há uma leitura perfeita, absolutamente irretocável e para sempre verdadeira, há, pelo menos, leituras mais próximas e leituras mais distantes do modo de ser das coisas, de sua dinâmica e transformação. 


\section{Avanços no século XX}

Ao século XX têm-se atribuído várias expressões. Ele é chamado de "século dos horrores" porque foi palco de duas guerras mundiais, genocídios de toda ordem, campos de concentração nazistas. É também considerado como o portal do que se convencionou chamar de "sociedade do conhecimento", uma expressão um pouco estranha por dois motivos. Em primeiro lugar, porque todas as sociedades humanas se organizam e se nutrem por meio do capital coletivo de conhecimentos acumulados e emergentes. Mesmo que a sociedade contemporânea consagre o conhecimento como o epicentro que a caracteriza, a seqüência evolutiva que se desdobra em sociedades nômades, agrícolas, industriais, pós-industriais e, por fim, do conhecimento, isso induz a simplificações e homogeneizações perigosas. Em segundo lugar, porque conforme discutimos anteriormente, a quantidade e velocidade da produção de informações na sociedade globalizada não redunda necessariamente em conhecimento, mas num acervo incontrolável de dados e na rapidez e visibilidade excessiva das informações - o que dificulta o processo de organização, reflexão, compreensão. Se montamos a expressão "sociedade do conhecimento", seria importante qualificá-la por meio do vocábulo fast - "sociedade do conhecimento fast"- como uma força de distingui-la das que nos precederam no tempo e às quais poderiam referir-se como "sociedades do conhecimento slow". No livro Alfabetização ecológica (2006), Maurice Holt, Alice Waters e Fritjof Capra, entre outros, avaliam os efeitos negativos, e mesmo predadores, de uma educação cujos princípios curriculares são orientados pela quantidade excessiva de informações, sem o necessário tempo para os estudantes as tratarem e refletir sobre elas. Um tal cardápio curricular acaba por provocar uma indigestão mental, além de facilitar uma cultura de cidadãos cujo desejo predominante é ter sempre mais uma porta aberta para o individualismo e o descompromisso com a sociedade do presente e do futuro. No referido livro, e com base em experiências curriculares inovadoras, os autores propõem os ideários do que chamam de Slow School.

Em essência, a palavra slow se tornou uma metáfora de uma maneira de abordar as questões práticas. Daí a idéia de slow school, que não significa ler em velocidade reduzida para pessoas vagarosas. A slow school trata da filosofia, da tradição, da comunidade e de escolhas morais. O aluno tem tempo não apenas para memorizar, mas também para entender o que está sendo ensinado (HOLT, 2006, p. 88). 
Ampliando esse panorama, Daniel Quin, no livro Ismael: um romance sobre a condição humana, caracteriza por meio de duas expressões provocativas, dois tipos de modelos civilizacionais. Chamam-se de "pegadores" e "largadores" os dois estilos culturais de viver em sociedade. O primeiro estilo - os pegadores - diz respeito a um modo de viver em mais sintonia com o mundo e alimentado por grandes narrativas retotalizadoras da vida humana no planeta. O segundo estilo - os largadores - caracteriza a sociedade ocidental moderna cultivadora do mito do progresso, parcelarizada e alimentada pelos valores da substituição e velocidade. Certamente esse artifício metafórico da literatura permite avaliar os efeitos predadores do pensamento mutilante nas "sociedades de mercado" no interior dos quais a educação passa a ser uma moeda de troca, um bem comercializável.

De qualquer modo, como o conhecimento é uma manifestação da cultura, suas formas de expressões e enunciativas estão em estreita simbiose com a história vivida em cada tempo e o contexto geopolítico-social das sociedades humanas. Mais que isso, como a aventura humana é sempre maestrada, simultaneamente, pelas forças de disjunção e da conjunção, e pela dialógica entre ordem e desordem, é possível identificar focos de emergências revitalizadores da cultura, do conhecimento e da educação. Isso explica porque é somente no século XX que do interior do conhecimento científico emergem certas noções, conceitos, novas áreas de conhecimento e ciências emergentes. Pari passu com os intensos fluxos da comunicação global que apagam as fronteiras nacionais, continentais e terrestres, vão sendo elaboradas novas ferramentas cognitivas até então sem condições históricas para nascer, ou asfixiadas pelo pensamento da fragmentação. "La revolución científica del siglo XX conduce a la vinculación, contextualización y expresión de la totalidad en que se encuentran relacionados saberes artes considerados fragmentarios y compartimentados" (MORIN: 2008b, p. 5).

Num panorama que consolida cada vez mais o processo de globalização iniciado com o descobrimento da América, tem-se agora a chance cognitiva de construir compreensões que se baseiam em noções como sistemas e organização. Para Morin, essas duas noções "tienem importancia crucial para la compreensión de las transformaciones educativas que necessitamos" (MORIN, 2008b, p. 5). O contexto planetário permite e facilita o trânsito das noções de ordem da ciência clássica para a noção de organização, ou seja, o modo de ser de um conjunto constituído por interações e retroações que se organiza a si mesmo. Essa compreensão desfaz a idéia clássica de uma natureza inerte, neutra, destituída de fluxos de reorganização própria. Transitamos também da noção de objeto para a de sistema e passamos à consideração de sistemas complexos nos quais as partes e o todo se produzem sempre em conjunto e se organizam mutuamente. 
Essas considerações de Edgar Morin sobre as contingências do século XX como facilitadoras de uma nova organização do conhecimento em bases complexas e transdisciplinares, bem como sobre a emergência de um "pensamento ecologizado", permitem compreender o estatuto epistemológico da ciência do complexo no mundo atual. Dito de outro modo, longe de um modismo, de um operador cognitivo abstrato, ou mesmo do surgimento de mais uma teoria para interpretar o mundo, as noções de complexidade, pensamento complexo e religação de saberes devem ser compreendidas como imperativos do nosso tempo, como uma forma de organizar conhecimentos em estreita ligação com o modo de organização dos domínios físicos, materiais, simbólicos, ecológicos, educacionais. Se é correto afirmar que a compreensão da interdependência múltipla dos fenômenos (sejam eles físicos ou culturais) só poderia emergir de uma sociedade-mundo em intensa interdependência, é igualmente razoável afirmar que uma "reforma do pensamento e da educação" em bases complexas configura, ao mesmo tempo, ferramentas cognitivas e sugestões pragmáticas essenciais para viver, conhecer e projetar novos horizontes civilizacionais.

\section{Ecologia das idéias, educação para a vida}

Favorecer a consciência da incerteza e da aposta e uma sensibilidade mais plena do sujeito diante de si e do mundo, talvez sejam princípios fundamentais a resguardar para fazer nascer um outro modo de conhecer. Mas é preciso dizer que, ao contrário do que normalmente pensamos, a abertura de vetores de sensibilidades mais plenos não advirá - principalmente, nem preferencialmente - das reformulações teóricas, conceituais, axiomáticas, metodológicas. Essa abertura certamente emergirá de sujeitos que se cobrem uma auto-organização, ou seja, que se exercitem como sujeitos implicados no mundo, na teia da vida, no conjunto social, na construção mítica, nos desmandos da civilização, na poética da natureza, no destino da espécie, na servidão dos despossuídos das benesses do progresso, nas reminiscências dos torturados dos campos de concentração nazistas, na curiosidade das crianças, no perigo de extinção das espécies, na obstinação de projetar e fazer acontecer uma verdadeira convivência humana, no empenho do fazer nascer uma nova humanidade.

Sentir-se implicado nos vários domínios dos quais nos constituímos e somos dependentes - o domínio da vida (somos um ser vivo, portanto, biodegradável); o domínio da matéria (somos um ser corpóreo, material); o domínio da humanidade (somos seres da quimera, do sonho, da imaginação, da palavra, 
o único animal que diz “era uma vez”, conta sua história) - pode ser entendido como princípio primeiro para fazer emergir uma educação complexa e transdisciplinar tão falada hoje e, paciente e ousadamente construída por Edgar Morin, ao longo de uma obra monumental circunscrita, sobretudo em seus últimos livros direcionados à reforma do ensino.

A autoformação tem aqui um papel importante e especial que requer um empenho sistemático e cotidiano. Os estudantes não devem esperar que seus professores os presenteim com um "kit básico" que permite religar saberes, áreas de conhecimento, domínios do mundo. Os professores foram formados seguindo os parâmetros da disciplinaridade, da especialidade, em sua grande maioria. Fazem, é verdade, um esforço enorme para aprender a religar parte e todo, fenômeno e ambiente, vida e idéias, mas estão, também como os alunos, aprendendo a aprender em novas bases, a partir de outros argumentos, de novas experiências fenomênicas, cognitivas. Além do mais, todo conhecimento se dá a partir de um sujeito - por si, em si, para si. Ninguém conhece no lugar de ninguém. Ninguém se transforma senão a partir de si próprio, de suas próprias experiências e aprendizagens. Conhecimento não se transfere, mais propriamente se organiza a partir da experiência do sujeito, de sua curiosidade, de seu espanto interrogativo, de sua construção. É nesse sentido que dizemos que todo conhecimento é subjetivo, apesar de ser compartilhado socialmente. Por outro lado, a idéia de complexidade, que é uma outra forma de falar da religação dos saberes, é uma emergência, está ainda engatinhando no interior da ciência da fragmentação, da disjunção, da separação. Por isso a autoformação, a aprendizagem do sentir-se implicado, do experimentar outras circunstâncias, do sair do domínio da especialidade para posteriormente voltar a ela mais acrescido, é essencial para aprender que as coisas com as quais lidamos ou queremos conhecer são multidimensionais, complexas. Sem essa experimentação do sujeito, noológica e fenomenal, não há possibilidade de religação das áreas de conhecimento.

Por outro lado, não há nada de muito complicado nisso, uma vez que nossa história biológica e cultural foi construindo, ao longo dos séculos, uma aptidão importantíssima: a empatia. No livro Eu, primata: por que somos como somos, o biólogo holandês, Frans de Waal discute a origem primata dessa nossa capacidade de imaginar o que o outro sente, a partir do que sentimos nós próprios. Essa aptidão para compreender o outro, penso eu, está na base do que pode vir a ser uma ferramenta importante para transversalizar domínios de experiências distintas. Como parece tratar-se de uma dinâmica de nossa psique - mecanismo de projeção, por exemplo - aqui estaria uma das bases do antropomorfismo, isto é, do fato de imprimirmos significados e propriedades humanas ao que não é humano. Mesmo que para Gaston Bachelard, no seu clássico ensaio intitulado A psicanálise do conhecimento objetivo, essa aptidão seja considerada um 
"obstáculo epistemológico", devemos discutir o aspecto virtuoso desse obstáculo. Por meio dele podemos operar o sentimento de parentesco entre nós e os sistemas vivos e não vivos. Os físicos, por exemplo, falam de "berçário de estrelas", da "placenta" que será rompida em determinando tempo para fazer nascer um conjunto de estrelas. Por quê? Porque entre nós humanos o ato de nascer supõe o rompimento da placenta, e, nas clínicas, os recém-nascidos ficam em berçários. Quando estudam o céu, os astrofísicos se valem, portanto, da analogia entre o fenômeno do nascimento dos humanos e das estrelas. O que é, pois, um obstáculo epistemológico - imputar qualidades humanas ao que não é humano - pode facilitar a consciência de nosso parentesco com o mundo no qual estamos imersos. Certamente por meio dessas ferramentas cognitivas estaremos avizinhando domínios distintos e compreendendo dinâmicas ou propriedades que os transversaliza e reúne.

A experiência de parentesco e simbiose do sujeito com o mundo é condição necessária - mesmo que não suficiente - para a religação de saberes, conhecimentos, áreas e domínios da ciência. O problema é que construímos sempre paradigmas, e a partir do século XVII, sobretudo os modelos de pensar, que se regem pela obsessão em separar e opor natureza e cultura, homem e meio ambiente, objetividade e subjetividade, matéria e espírito, fantasia e realidade, imaginação e realidade. Quando éramos crianças não experimentamos essas oposições: o bicho-papão era tão real (apesar de não material) que nosso coração batia enlouquecido, ficávamos lavados de suor quando ele se fazia presente em nossa imaginação. À medida que fomos crescendo, fomos distinguindo, aos poucos, a imaginação da realidade. Isso é um ganho em complexidade, é claro. Passamos a compreender um princípio de realidade que se distingue do fenômeno do delírio, e assim por diante.

A regressão em complexidade vem depois. Vem quando, além de distinguir, somos treinados social e culturalmente para separar e opor de forma inconciliável realidade e imaginação, material e imaterial, biológico e metabiológico. Ora, distinguir não é separar. Distinguir é reconhecer domínios diversos, coisas distintas. Separar e opor é desconhecer a relação, a simbiose e a hibridação entre domínios diversos e entre coisas distintas. Nada melhor para compreender a dialógica entre distinção e complementaridade do que a noção de ecologia. As ciências ecológicas que nascem no século XX sabem bem as relações estreitas que constituem os elos indissociáveis entre os seres vivos, seu meio natural, os fenômenos físicos e a ação do homem. Lamentavelmente, as ciências do homem nem sempre construíram conhecimento com base numa atitude de religação e no reconhecimento da multidimensionalidade de qualquer fenômeno. Esquartejada pelas distintas especialidades não comunicantes, a noção de homem se reduz às vezes à determinação biológica, outras vezes à determinação 
psíquica. Ora o homem é definido como ser social, ora como individual, ora como indivíduo determinado pelas condições históricas, ora como sujeito da liberdade e da autonomia sobre seu destino. Como nos ensina Edgar Morin, o homem é um sapiens-demens, indivíduo parasitado pela sabedoria e pela loucura, simultaneamente físico e metafísico, histórico e transhistórico, individual e coletivo, singular e genérico, movido por mecanismos bioquímicos e também por sonhos, ilusões, imaginários, por uma psique fabulosa. Ser da palavra e da contemplação, capaz de expressar o ato mais estético e sublime e igualmente $\mathrm{o}$ ato mais violento e infame. $\mathrm{O}$ romance e a poesia falam quase sempre dessa unidualidade e multiplicidade do humano. Por que será que a ciência separa? Será pura idiotice o poema de Augusto dos Anjos que diz "a mão que afaga é a mesma que apedreja, a boca que beija é a mesma que escarra"? Não sabemos disso por nossa próxima experiência cotidiana? Não nos reconhecemos como um sujeito ao mesmo tempo da ternura e da ira? Por que será que quando vamos delimitar nossos temas de pesquisa, nossas categorias de análise, o fazemos quase sempre a partir do ponto de vista de que as coisas são separadas e opostas? Esse é um ponto importante: será que não vivemos, nós próprios, de forma cindida, esquizofrênica?

Diante de tudo isso, é necessário assinalar que a religação dos conhecimentos e uma ecologia das idéias não virá por meio de receitas de pesquisa dos tão numerosos manuais de metodologia.

É de um sujeito impregnado pelo desejo dessa metamorfose que se pode esperar uma reformulação do conhecimento científico e da educação em bases transdisciplinares e complexas. É sobretudo da auto-organização de sujeitos implicados na experiência da diversidade - real e existencial - que podem emergir construções narrativas e práticas sociais reorganizadoras da sociedade terrena em novos patamares e limites. É crucial prefigurar e construir sociedades onde seja não só possível viver, mas onde seja bom viver. Dessa perspectiva, cabe à educação e ao esforço pessoal de cada estudante na autoformação, o desafio de construir coletivamente um ideário e uma prática de sociedade pautados pelos princípios da multiplicidade, da diversidade, da inclusão e da troca mais igualitária de experiências entre professores e alunos, entre escola e comunidade, entre as esferas da política e da educação. Construir coletivamente quer dizer facilitar a expressão das experiências que são, todas elas, múltiplas e unas, diversas e marcadas pela semelhança. Todos nós temos nossas histórias pessoais, familiares, amorosas, intelectuais. E, se não podemos transferir experiências, podemos narrá-las e compartilhá-las. Isso é ganho em conhecimento, isso é religação de vida e conhecimento, isso é compartilhar narrativas de experiências que pode se prolongar no compartilhar de idéias abstratas e experiências de pesquisa.

Se a sociedade-mundo expressa claramente a necessidade da co-partilha 
nos horizontes comuns e, mais que isso, reclama por laços efetivos e afetivos de convivência na diversidade, talvez tenhamos que exercitar uma verdadeira aeróbica dos neurônios para reconhecer que nossa autonomia e singularidade como humanos emergem justamente da dependência essencial que nos liga ao que excede ao propriamente humano. Na base das atitudes de intolerância ao diverso e de descompromisso com a sociedade do futuro está um padrão de conceber o mundo, a matéria, a vida. Crianças e adolescentes que não aprenderam porque não experimentaram os valores da parcimônia e do companheirismo certamente terão mais dificuldade de compreender e exercitar a solidariedade e a gratuidade dos afetos alargados, exogâmicos e universais de que tanto necessitamos hoje. Crianças e adolescentes que experimentaram excessivamente a contingência do pronome possessivo meu (meu país, meu lugar, minha religião, minha família, meus amigos e meus inimigos, minha casa, meu gato) certamente terão mais dificuldade para abraçar o projeto do nosso destino comum, dos nossos erros e acertos coletivos e a consciência de que o mundo não começa nem termina no umbigo de cada um. Crianças e adolescentes que experimentaram excessivamente os valores do descartável terão dificuldade, certamente, de inserir o outro na dialógica do eu; terão dificuldade de, não só aceitar, mas sobretudo apreciar, gostar e aprender com a diversidade dos modos de viver. Terão, acima de tudo, dificuldade em ultrapassar a oposição meu $x$ deles por uma consciência que inclua a sintonia universal entre os seres humanos e todas as coisas do mundo. Mas por outro lado, crianças e adolescentes que não viveram a condição de pertencer a uma família ou a um grupo para fixar a aprendizagem dos afetos (CYRULNIK, 2004) terão dificuldade de fazer desabrochar solidariedades alargadas. Daí porque o etólogo referido entende que os professores devem ser "tutores do afeto". É crucial que cada um de nós, professores e estudantes, arquitetemos cenários que não nos ofereceram, sonhos que foram abortados, lugares cognitivos mestiços para habitar, experimentar, explicitar.

Nos novos cenários que cabem a nós próprios construirmos haveremos de desenhar um mapa aberto e inacabado que possa ser completado, acrescido e transformado coletivamente. Aqui "as ações individuais continuam a serem essenciais" (PRIGOGINE, 2001) como ingredientes singuladores a serem absorvidos pela ecologia das idéias.

Aprender a viver e facilitar uma ecologia dos saberes são condições necessárias para desenharmos um novo mapa do conhecimento, da ciência, da sociedade. É a partir do lugar que cada um de nós ocupa que essa ecologia emergirá. Ela terá sempre a nossa cara, se nutrirá sempre de nossas apostas pessoais para elaborar uma compreensão mais complexa do mundo. Ela é possível, mas depende da ousadia de um sujeito que seja, ele próprio ecológico e diverso em suas experiências. 
Uma nova educação está surgindo. Ela será o que quisermos que ela seja, em grande parte. A outra parte fica por conta do acaso e da incerteza. Façamos nossas apostas!

\section{REFERÊNCIAS}

BACHELARD, G. A psicanálise do conhecimento objetivo. In: .Epistemologia: Trechos escolhidos. Rio de Janeiro: Zahar Editores, 1977.

CAPRA, F. et al. Alfabetização ecológica - a educação das crianças para um mundo sustentável. Michael K. Stose; Zenobia Barlow (Org.). São Paulo: Cultrix, 2006.

CYRULNIK, B. Os patinhos feios. São Paulo: Martins Fontes, 2004.

HOLT, M. A idéia da slow school: é hora de desacelerar a educação? In: CAPRA, Fritjof et al. Alfabetização ecológica - a educação das crianças para um mundo sustentável. Michael K. Stose; Zenobia Barlow (Org.). São Paulo: Cultrix, 2006.

MORIN, E. A cabeça bem feita. Rio de Janeiro: Bertrand Brasil, 2000.

MORIN, E. Planetarización y crisis de la humanidad In: Educación. Revista de Educación Moderna para una Sociedad Democrática, n. 152 - enero 2008. México: Cia Impresora y Editora ANGEMA. 2008a.

MORIN, E. Reforma la educación, la enseñanza, el pensamiento. In: . Este País. Tendencias y opiniones. México: Camara Nacional de la Industria, Editora Mexicana, 2008b.

PRIGOGINE, I. Ciência, razão e paixão. In: ALMEIDA, M. da C.; CARVALHO, E. de A (Org.). Ciência, razão e paixão. Belém: EDUEPA, 2001.

ROSNAY, J. O homem simbiótico - perspectivas para o terceiro milênio. Petrópolis: Vozes, 1997.

SHIVA, V. Monocultura da mente: Perspectivas da biodiversidade e da biotecnologia. São Paulo: Gaia, 2003.

SILVA, F. L. da. A natureza me disse. Organização de Maria da Conceição Xavier Almeida; Paula Vanina Cencig. Natal: Flecha do Tempo, 2007.

WAAL, F. de. Eu primata: por que somos como somos. São Paulo: Companhia da Letras, 2007. 